\title{
The Effectiveness of a Behavioral Program in Reducing the Aggressive Behavior of Children with Mild Mental Disabilities at the Mu'tah Center for Special Education
}

\author{
Sameer Alremawi ${ }^{1}$, Ahmed A. Arabiyat ${ }^{1}$ \\ 1 Department of Psychology and special education, Al-Balqa Applied University \\ Keywords: The collective program, Behavioral school, Aggressive behavior, Mental disability \\ https://doi.org/10.52965/001c.32317
}

Health Psychology Research

Vol. 10, Issue 1, 2022

\begin{abstract}
The study aimed to identify the effectiveness of a behavioral counseling program's in reducing aggressive behavior among children with mild mental disabilities at the Mu'tah Center for Special Education. The study sample consisted of (10) male and female students with mild mental disabilities, whose ages ranged between (10-14) years. The one group system (the experimental group) was used. The list of aggressive behavior was applied to the study sample in three stages: The first stage was a baseline (pre-test) and lasted a week, and the second stage was a stage after the completion of the application of the guidance program (post-test), where it lasted for six weeks, while the third stage was the (follow-up measurement) phase, which was carried out two months after stopping the implementation of the program, the repetitions of aggressive behavior were counted. The study used the Wilcoxon Matching Pairs Signed test to calculate the differences between the mean of the pre-test scores and the mean of the post/test scores. The study found the following results: There were differences between the study sample members in the two measurements (pre and post) in the relative weight of the study sample and in favor of the post-test, which indicates the effectiveness of the behavioral counseling program. The results also indicate no statistical differences between the study sample members in the two measures (post and follow up), which indicates the continuity of the effectiveness of the behavioral counseling program.
\end{abstract}

\section{INTRODUCTION}

Caring for children in general and the disabled in particular is a concern for the whole of society, and the progress and advancement of societies is measured by the extent of their interest and care for them and work to develop their various skills. ${ }^{1}$ The phenomenon of mental disability is not limited to developing societies only, but rather exists in civilized societies that are interested in developing the intelligence and skills of their citizens to achieve the best opportunities for social harmony. ${ }^{2}$ A significantly high rate of mental disability in the countries was reported in literature. ${ }^{3}$

Education has developed in our time; It is no longer confined to ordinary individuals, and education is no longer directed only to people with medium and high mental abilities as in the past. ${ }^{4}$ Rather, societies have given special importance to people with disabilities, believing in the principles of human rights such as the principle of equal opportunities for all individuals according to their abilities and readiness, whether they are disabled or normal. ${ }^{5}$

The problem of mental disability is one of the most severe and most serious problems of children. ${ }^{6}$ The presence of a disabled child within the family affects the lives of the members of this family, especially if it is accompanied by aggressive behavior with their disability and the way the family interacts with society is affected, ${ }^{7}$ especially in fam- ilies that deny the existence of a disability in their children, which negatively affects the integration of the disabled in the community. ${ }^{8}$

In the most recent publications of the American Society for Mental Retardation, a definition appeared that included specific dimensions of adaptive behavior and is considered more general and comprehensive in its content, and states that "mental retardation refers to a fundamental deficiency in a person's current functional abilities, ${ }^{9}$ which is characterized by a clear deficiency in mental function, accompanied by a relative deficiency in two or more of adaptive behavior skills, which are communication, self-care, health and security, academic performance, and free time, and work to show that before the age of eighteen. 10,11

The phenomenon of mental disability is one of the common phenomena that has existed throughout the ages, and almost no society is devoid of it. Interest in this phenomenon is returned in various fields such as: psychology, education, medicine and law, and the reason for this is due to the multiplicity of scientific bodies that contributed to the interpretation of this phenomenon and its impact on society. ${ }^{12}$ This phenomenon also has a manifold extension in several dimensions, including: educational, professional, psychological and social. This led to the intertwining of its dimensions so that it became difficult to separate them when dealt with research and study. ${ }^{13}$ This has contributed 
to the multiplicity of concepts of mental disability according to the specialization and according to the theoretical background and the scientific field, and there was no single definition agreed upon, except that everyone participated in the general meaning of deficiency or mental retardation. 14,15

The mentally disabeled individuals are characterized by a number of general characteristics and traits that make them different from other normal children, and among these characteristics and traits: ${ }^{16}$ the lack of the ability to pay attention, focus, perception, imagination, thinking and understanding, and the lack of verbal communication ability, in addition to that society is the one who failed to understand their abilities and potentials, and understanding the mentally disabeled as a result is a relative matter, and the solutions provided to the disabled are individual solutions. ${ }^{16}$ From this point of view, the mentally disabeled child has many skills that an individual's needs to develop and take care of through training programs, and out of belief in the right of these groups to a human life. ${ }^{17}$ Generous Legislations were issued that affirmed their right to integrated care, and the circle of care expanded to include groups that are not able to learn, and international conventions contributed to making radical changes in the care of the disabled. ${ }^{18}$

\section{RESEARCH PROBLEM AND QUESTIONS}

Aggressive behavior is a challenge facing teachers of mentally disabled children, and it hinders the educational process for them. It is considered one of the most important reasons behind the failure of the mentally disabled in personal and social adaptation and prevents their integration into society. ${ }^{19}$

Those working with children with mental disabilities often face some behavioral problems, they may find it difficult to deal with them, and resort to developing appropriate solutions. One of these behavioral patterns is aggression, which affects the educational process and the social adjustment of the disabled and makes them undesirable. The researchers set out to build a behavioral program that helps those working with children with mental disabilities to reduce their aggressive behavior. Through observation, it was found that one of the main problems that hinder the work of the teacher in the classroom is aggression, and aggression may affect the mentally disabled and the aspects of his/her personality. The advantage of the study is that the behavioral counseling program relied on reducing aggression. It is hoped that it will be an addition in this program. Accordingly, the problem of the study crystallizes in an attempt to answer the following main question: - What is the effectiveness of a behavioral program to reduce aggressive behavior among children with simple mental disabilities at Mutah Center for Special Education? From the main question, the following sub-questions emerge:

- Are there statistically significant differences at the level of significance $(\alpha \leqslant 0.05)$ in the mean scores of the study sample (with simple mental disabilities) in the pre and post measurements on the aggressive behavior scale due to the counseling program?
- Are there statistically significant differences at the level of significance $(\alpha \leqslant 0.05)$ in the mean scores of the study sample (with simple mental disabilities) in the pre and post measurements and follow-up measurements on the aggressive behavior scale due to the continued effectiveness of the counseling program?

\section{PURPOSE OF THE STUDY}

The present study aimed to

Investigating the effectiveness of a behavioral program in reducing aggressive behavior among children with mild mental disabilities at Mutah Center for Special Education.

\section{LIMITS OF THE STUDY}

Locative limits: Mutah Center for Special Education in Karak Governorate for people with mild mental disabilities between (10-14) years.

Time limits: the second semester of the academic year 2019/2020.

Human limits: determined by the sample used consisting of (10) students of both sexes who are enrolled in the Mu'tah Center for Special Education with simple mental disabilities, according to the diagnosis approved by the center.

\section{METHODOLOGY}

The study sample: After applying the scale to the total sample consisting of (15) male students and (9) female students from Mutah Center for Special Education, (10) of them were selected, (6) males, and (4) females. Those who obtained the highest scores on the study scale, and the behavioral counseling program was applied to them.

\section{THE STUDY DESIGN}

The researchers used the semi-experimental approach, which is one of the most appropriate approaches in line with the study problem and its objectives. The current study aims at the effectiveness of a counseling program in reducing aggression behavior for people with mild mental disabilities at the Mutah Center for Special Education in Karak Governorate.

\section{DATA COLLECTION TOOLS}

The first tool: the aggressive behavior scale, which was developed by researchers according to the following steps:

A. The researchers referred to the Birx scale, the adaptive behavior scale in the Jordanian environment, and the aggressive behavior scale. ${ }^{20}$

B. The researchers developed a scale of aggressive behavior, where the scale consisted of phrases representing behavioral patterns indicating aggressive behavior, which in its initial form amounted to (42) statements, and the teacher was asked to observe the behavior of the sample members for (45) minutes each time, and put a sign (/) in front of each paragraph when the sample members perform the behav- 
ior that represents the behavioral pattern indicated by the statement. Then the frequencies are collected so that the minimum for this behavior is one and the maximum is not determined by a specific frequency and depends on the extent to which the sample members repeat the behaviors.

C. The validity of the scale was verified by presenting the statements of the scale to a group of jury members consisting of (10) members of the teaching staff in the College of Educational Sciences, and five teachers working in the field with people with disabilities. The statements that reached $80 \%$ or more were accepted. The statements that were referred to as necessary were amended and added, in addition to deleteing the statements that their agreement percentage were less than $80 \%$.

D The scale was verified using the test-retest method, where the tool was applied to (15) students from the study population and from outside the sample. After two weeks, the application was performed again, then the reliability coefficient was calculated, and it was (0.87), which is suitable for such a study.

The scale, in its final form, after validation, consisted of thirty-eight items divided into three areas:

- Self-directed aggression (1-8)

- Aggression directed at others (9-30)

- Aggression directed at property (31-38)

The second tool is the behavioral counseling program:

The researchers prepared a behavioral program based on the techniques of behavior modification, in order to use it with a sample of students who show aggressive behavior with mild mental disabilities. The researchers presented the counseling program before applying to a group of professors specialized in psychological counseling and special education, who kindly provided their feedback on the counselling programme. What was agreed upon (80\%) and above was added and corrected, and what was less than (80\%) was deleted.

\section{APPLICATION OF THE COUNSELING PROGRAM}

The counselling program was implemented through some steps mentioned by the researchers in the following points:

1. Training of female teachers first by researchers on the mechanism of applying the program and how to implement sessions with the participation of researchers.

2. The agreement between the researchers on the one hand and the study sample on the other hand to adhere to the sessions, and whoever abides by the instructions has an award.

3. The program was implemented in the second semester of the academic year 2019-2020 at the Mutah Center for Special Education.

4. The counseling sessions were carried out according to the set plan and lasted (12 sessions, two sessions per week, and the duration of each session was " 30 minutes".

5. The sessions were carried out collectively.

\section{THE CONTENT OF THE COUNSELLING PROGRAM}

The program included 12 group counseling session based on the use of behavior modification techniques. The following table summarizes the number of sessions, their titles, objectives and implementation date.

Techniques used in the program: The most important techniques used in this program are the principles and techniques of the behavioral curve to modify behavior, through the use of play and the associated accompanying activities such as modeling, role playing and behavior enhancement through material or moral rewards, in addition to a set of experiences, practices and the educational activities aimed at decreasing the aggressive behavior of these children are as follows:

Group play: The counseling program used in this study included group play sessions and training in interaction through participation with peers in order to provide the child with personal and social skills (a set of games and practices carried out by the children of the experimental group under the supervision of researchers in cooperation with the responsible educator, who seeks the ability of children on social interaction, cooperation, and employment of children's energies and limited capabilities in line with their abilities, inclinations and preparations in an atmosphere of tranquility, friendliness, love and a sense of mutual acceptance between children and researchers

Movement activity: It is free play inside or outside the classroom. The child engages in loving activities that create an atmosphere of intimacy, love and affection among children while bringing joy and pleasure in them.

Artistic activity: It is one of the children's favorite activities because it is a means of venting pent-up emotions and feelings, and it is a means of social and psychological growth, and it is a means of solving many psychological problems.

Storytelling activity: The story is characterized by the ability to attract attention, suspense and provoke imagination, so it can be an effective element in the mental and emotional development of the child. The child, by nature, loves stories and follows their events, so the stories have a significant effect in modifying behavior, reducing aggressive behavior, gaining self-confidence and learning proper values and habits.

\section{RESULTS}

To answer the first research question stating that

Are there statistically significant differences at the level of significance $(\alpha \leqslant 0.05)$ in the level of aggressive behavior for people with mild mental disabilities in the pre and post measurement?

To answer this question, the researchers applied the study tool to the students of the study sample before starting the application and after applying it, and due to the sample size and its unsuitability for the assumptions of the parametric tests, the (Wilcoxon Matched Pairs Signed) test was used, which is one of the appropriate nonparametric tests to detect the presence of significant statistical differences between the two applications, pre and post (Table 2). 
Table 1. A summary of the counselling program sessions

\begin{tabular}{|c|c|c|c|c|}
\hline Session & Brief Aims & Activity & Methods & Time \\
\hline $\begin{array}{l}\text { First } \\
\text { Session }\end{array}$ & building intimacy & $\begin{array}{l}\text { Meeting and } \\
\text { introduction to the } \\
\text { program and its } \\
\text { objectives }\end{array}$ & Badges & $\begin{array}{l}30 \\
\text { Min }\end{array}$ \\
\hline $\begin{array}{l}\text { Second } \\
\text { Session }\end{array}$ & $\begin{array}{l}\text { Increased attention, focus and adherence to } \\
\text { instructions }\end{array}$ & $\begin{array}{l}\text { Kinetic activity to } \\
\text { join beads }\end{array}$ & $\begin{array}{l}\text { String, beads, white } \\
\text { and red balloons, } \\
\text { ready-made } \\
\text { necklace }\end{array}$ & $\begin{array}{l}30 \\
\text { Min }\end{array}$ \\
\hline $\begin{array}{l}\text { Third } \\
\text { session }\end{array}$ & Recognize colors and accept win and loss & $\begin{array}{l}\text { Movement activity, } \\
\text { balloon popping }\end{array}$ & $\begin{array}{l}\text { red and blue } \\
\text { balloons }\end{array}$ & $\begin{array}{l}30 \\
\text { Min }\end{array}$ \\
\hline $\begin{array}{l}\text { Fourth } \\
\text { session }\end{array}$ & $\begin{array}{c}\text { Discharge excess energy with purposeful } \\
\text { movements }\end{array}$ & Art activity & $\begin{array}{l}\text { Cassette for } \\
\text { children's songs, } \\
\text { recorded }\end{array}$ & $\begin{array}{l}30 \\
\text { Min }\end{array}$ \\
\hline $\begin{array}{l}\text { Fifth } \\
\text { session }\end{array}$ & $\begin{array}{l}\text { Unloading internal repressions and expressing } \\
\text { them in a drawing }\end{array}$ & Art activity & $\begin{array}{l}\text { White paper, colors, } \\
\text { pencil }\end{array}$ & $\begin{array}{l}30 \\
\text { Min }\end{array}$ \\
\hline $\begin{array}{l}\text { Sixth } \\
\text { session }\end{array}$ & $\begin{array}{l}\text { Recognizing the right behaviors from the wrong } \\
\text { behaviors through acting }\end{array}$ & Role play & $\begin{array}{l}\text { Character dolls, cats, } \\
\text { recorder and } \\
\text { cassette }\end{array}$ & $\begin{array}{l}30 \\
\text { Min }\end{array}$ \\
\hline $\begin{array}{l}\text { Seventh } \\
\text { session }\end{array}$ & $\begin{array}{c}\text { Recognize right behavior and wrong behavior } \\
\text { through colors }\end{array}$ & Coloring & $\begin{array}{l}\text { Holograms, colors, } \\
\text { display board }\end{array}$ & $\begin{array}{l}30 \\
\text { Min }\end{array}$ \\
\hline $\begin{array}{l}\text { Eigth } \\
\text { session }\end{array}$ & $\begin{array}{l}\text { Accepting profit and loss, physical contact with } \\
\text { others and not hurting them }\end{array}$ & movement activity & chair set, prizes & $\begin{array}{l}30 \\
\text { Min }\end{array}$ \\
\hline $\begin{array}{l}\text { Ninth } \\
\text { session }\end{array}$ & Educational objective and get to know pets & Classification & $\begin{array}{l}\text { Animal cards and } \\
\text { their houses, pencil, } \\
\text { worksheets }\end{array}$ & $\begin{array}{l}30 \\
\text { Min }\end{array}$ \\
\hline $\begin{array}{l}\text { Tenth } \\
\text { session }\end{array}$ & Teamwork & movement activity & Balls, baskets, prizes & $\begin{array}{l}30 \\
\text { Min }\end{array}$ \\
\hline $\begin{array}{l}\text { Eleventh } \\
\text { session }\end{array}$ & Increase focus and teamwork & $\begin{array}{l}\text { disassembly and } \\
\text { assembly activity }\end{array}$ & cube set & $\begin{array}{l}30 \\
\text { Min }\end{array}$ \\
\hline $\begin{array}{l}\text { Twelfth } \\
\text { session }\end{array}$ & $\begin{array}{l}\text { Thank you to the students for completing the } \\
\text { orientation program, biding them farewell, and } \\
\text { reminding them of some daily life skills }\end{array}$ & Leisure activity & Prizes, candy, juice & $\begin{array}{l}30 \\
\text { Min }\end{array}$ \\
\hline
\end{tabular}

Table 2. Wilcoxon Matched Pairs Signed to identify the statistical differences in the aggressive behaviors among the study sample subjects between the pre and the post applications

\begin{tabular}{|c|c|c|c|c|c|c|c|c|c|}
\hline Domain & & Mean & $\begin{array}{l}\text { Standard } \\
\text { deviation }\end{array}$ & $\begin{array}{c}\text { Distribution } \\
\text { of ranks }\end{array}$ & $\mathrm{N}$ & $\begin{array}{l}\text { Mean } \\
\text { ranks }\end{array}$ & $\begin{array}{c}\text { Sum } \\
\text { of } \\
\text { ranks }\end{array}$ & Z & Sig \\
\hline \multirow{3}{*}{$\begin{array}{l}\text { Self-directed } \\
\text { aggression }\end{array}$} & Pre & 19.83 & 5.57 & Negative & 12 & 6.50 & 78.00 & -3.06 & ${ }^{*} 0.002$ \\
\hline & Post & 12.92 & 1.31 & Positive & 0 & .00 & .00 & & \\
\hline & Ties & 0 & - & - & & & & & \\
\hline \multirow{3}{*}{$\begin{array}{c}\text { Aggression } \\
\text { directed at } \\
\text { others }\end{array}$} & Pre & 60.25 & 9.71 & Negative & 11 & 6.00 & 66.00 & -2.93 & ${ }^{*} 0.003$ \\
\hline & Post & 48.33 & 8.90 & Positive & 0 & .00 & .00 & & \\
\hline & Ties & 1 & - & - & & & & & \\
\hline \multirow{3}{*}{$\begin{array}{c}\text { Aggression } \\
\text { directed at } \\
\text { property }\end{array}$} & Pre & 19.92 & 2.96 & Negative & 12 & 6.50 & 78.00 & -3.07 & ${ }^{*} 0.002$ \\
\hline & Post & 13.08 & 1.88 & Positive & 0 & .00 & .00 & & \\
\hline & Ties & 0 & - & - & & & & & \\
\hline \multirow{3}{*}{ Total } & Pre & 100.00 & 17.32 & Negative & 12 & 6.50 & 78.00 & -3.06 & ${ }^{*} 0.002$ \\
\hline & Post & 74.33 & 10.89 & Positive & 0 & .00 & .00 & & \\
\hline & Ties & 0 & - & - & & & & & \\
\hline
\end{tabular}

"Statistically significant at $(\alpha \leqslant 0.05)$

The data in Table 2) shows that there are statistically significant differences at the significance level $(\alpha \leqslant 0.05)$ in terms of the value of $(\mathrm{Z})$ and the level of significance ac- companying it between the aggressive behavior of the study sample members in the two applications, before and after, at the level of each domain of aggressive behavior (Self-di- 


\section{Variation in pre and post performance}

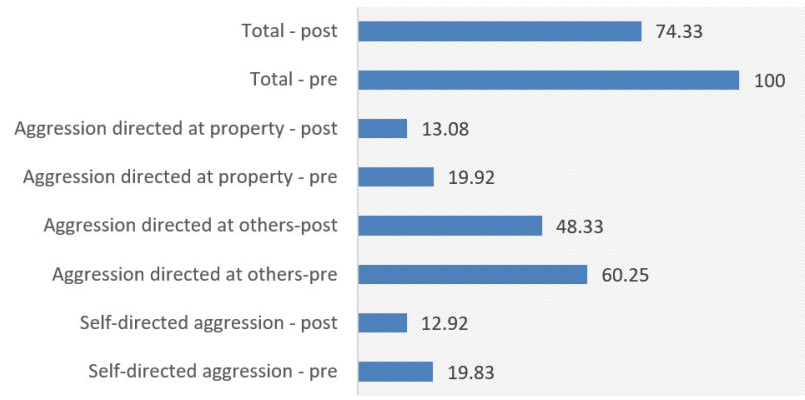

Figure 1. Variation in the pre and post performance of the study sample participants

rected aggression, aggression directed towards others, and aggression directed towards property) as well as the total level of aggression, and by reference to the mean scores, it appears that the average aggressive behavior in the post application is lower than in the pre application, which indicates a decrease in aggressive behavior after the study sample members were exposed to the counseling program. This result enhances the effectiveness of the counseling program in reducing the aggressive behavior of people with mild mental disabilities. Figure 1 shows the variation in the level of aggressive behavior between the post and follow up application at the total level of the study sample members

To answer the second research question stating that

Are there statistically significant differences at the level of significance $(\alpha \leqslant 0.05)$ in the level of aggressive behavior for people with moderate mental disabilities between the post and follow-up measurements?

To answer this question, the differences in the level of aggressive behavior of the study sample members were examined immediately after applying the program, and two months after this application of the follow up measurement. In view of the sample size and its unsuitability for the assumptions of the parametric tests, the Wilcoxon Matched Pairs Signed test was used, which is one of the appropriate nonparametric tests to detect the presence of statistically significant differences between the two applications, the pre and post applications. Table 3 shows the level of variation in aggressive behavior between the pre applications at the total level of the study subjects

The data in Table 3 show that there are no statistically significant differences at the significance level $(\alpha \leqslant 0.05)$ in terms of the value $(Z)$ and the level of significance accompanying it in the aggressive behavior of people with moderate mental disabilities in the two applications during the application of the program and the follow-up measurement at the level of each of the domains Aggressive behavior (Self-directed aggression, aggression directed towards others, and aggression directed towards property) and this result is reinforced by the retention of the study sample members with the effect of the program that is still effective in reducing their aggressive behavior at the level of all fields, As well as at the total level, despite the passage of a month since the completion of the application of the program. Fig-

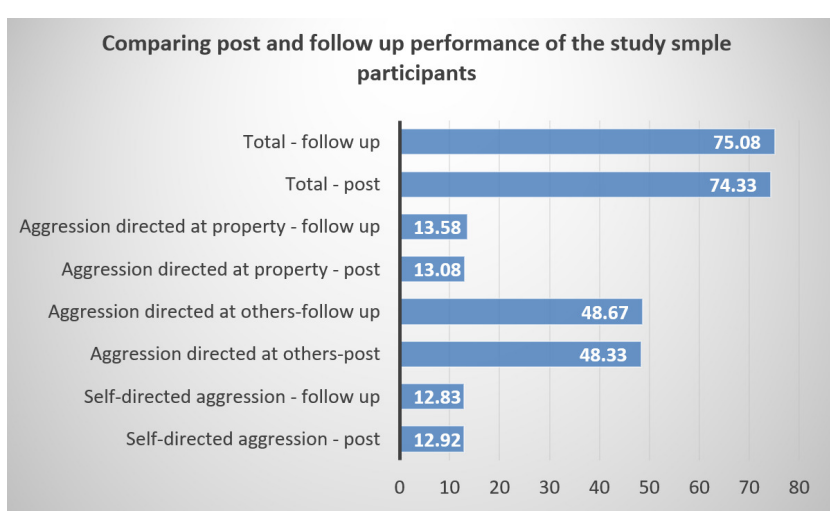

Figure 2. Comparing the level of performance between post and follow up applications on the study sample participants

ure 2 shows the convergence of the level of performance in the post and follow-up applications of the study sample as a whole.

\section{DISCUSSION}

Mental disability is a behavioral disorder with multiple causes and it is impossible to separate them and determine which of them as a direct cause. ${ }^{21}$ The number of known causes so far has reached more than 350 , and some researchers classify them into two main groups, first: genetic causes that lead to primary mental disability or mental disability that is due to internal factors. Second: The set of environmental causes that lead to acquired secondary mental disability, which are due to external factors. ${ }^{22}$ Despite the great efforts and achievements that have been achieved in uncovering the factors that lead to mental disabilities, many cases are still unknown causes, and most epidemiologists agree that about. ${ }^{22}$

There are many categories and classifications of mental disability depending on the multiplicity of its dimensions, the causes leading to it, and the multiplicity of characteristics and traits of the cases of this disability, ${ }^{23}$ which in turn vary according to the degree of disability, the time of its occurrence and its medical condition. ${ }^{24}$ As a result, scholars differ in the criteria they use as a basis for classifying the mentally disabled. ${ }^{23}$ There are medical classification, psychological classification, clinical classification, and educational classification. The mentally disabled are characterized by the vast individual differences between them and their lack of homogeneity or congruence in terms of their preparations and characteristics and traits. ${ }^{24}$ However, there are several general characteristics that should not be neglected when we try to detect and identify them and determine the educational rehabilitation programs for them, despite the recognition that they vary in terms of the degree of each characteristic according to the level of disability, environmental conditions and cultural influences to which they are exposed and interact with. ${ }^{25}$

The multiplicity of categories of mental disability, the multiplicity of causes leading to it and the multiplicity of its manifestations from one case to another makes the prob- 
Table 3. Wilcoxon Matched Pairs Signed to identify the statistical differences in the aggressive behaviors among the study sample subjects between the post and the follow up applications

\begin{tabular}{|c|c|c|c|c|c|c|c|c|c|}
\hline Domain & & Mean & $\begin{array}{l}\text { Standard } \\
\text { deviation }\end{array}$ & $\begin{array}{l}\text { Distribution } \\
\text { of ranks }\end{array}$ & $N$ & $\begin{array}{l}\text { Mean } \\
\text { ranks }\end{array}$ & $\begin{array}{l}\text { Sum } \\
\text { of } \\
\text { ranks }\end{array}$ & Z & Sig \\
\hline \multirow{3}{*}{$\begin{array}{l}\text { Self-directed } \\
\text { aggression }\end{array}$} & post & 12.92 & 1.31 & negative & 5 & 6.00 & 30.00 & -2.65 & 0.791 \\
\hline & $\begin{array}{l}\text { Follow } \\
\text { up }\end{array}$ & 12.83 & 1.94 & positive & 5 & 5.00 & 25.00 & & \\
\hline & Tier & 2 & - & - & & & & & \\
\hline \multirow{3}{*}{$\begin{array}{l}\text { Aggression } \\
\text { directed at } \\
\text { others }\end{array}$} & post & 48.33 & 8.90 & Negative & 4 & 6.00 & 24.00 & -0.86 & 0.403 \\
\hline & $\begin{array}{l}\text { Follow } \\
\text { up }\end{array}$ & 48.67 & 9.12 & Positive & 7 & 6.00 & 42.00 & & \\
\hline & Tier & 1 & - & - & & & & & \\
\hline \multirow{3}{*}{$\begin{array}{l}\text { Aggression } \\
\text { directed at } \\
\text { property }\end{array}$} & post & 13.08 & 1.88 & Negative & 1 & 2.50 & 2.50 & 1.73 & 0.084 \\
\hline & $\begin{array}{l}\text { Follow } \\
\text { up }\end{array}$ & 13.58 & 1.56 & Positive & 5 & 3.70 & 18.50 & & \\
\hline & Tier & 6 & - & - & & & & & \\
\hline \multirow{3}{*}{ Total } & post & 74.33 & 10.89 & Negative & 2 & 5.00 & 10.00 & 1.12 & 0.259 \\
\hline & $\begin{array}{l}\text { Follow } \\
\text { up }\end{array}$ & 75.08 & 11.48 & Positive & 6 & 4.33 & 26.00 & & \\
\hline & Tier & 4 & - & - & & & & & \\
\hline
\end{tabular}

*Statistically significant at $(\alpha \leqslant 0.05)$

lem of mental disability a difficult and complex problem. ${ }^{25}$ It cannot be considered just a measure of an individual's level of intelligence. There are other dimensions that must be taken into account when diagnosing a disability, because diagnosing mental disability means placing them within a certain category of children who need special education, care and appropriate rehabilitative treatment programs for them, so the diagnosis must be accurate. ${ }^{26}$

The field of care for the mentally disabled is one of the important areas in which behavior modification methods are used primarily to provide these children with the necessary skills for adaptive behavior (Teixeira et al., 2015), as well as in dealing with inappropriate behavior. ${ }^{27}$ Behavioral therapy includes treatment programs that are intended to reduce the rate of unwanted behavior or to eliminate this behavior permanently. ${ }^{28}$ It also includes training programs that aim to give the child a new behavior or increase the rate of practicing the desired behavior. ${ }^{29}$ The behavioral treatment model depends on special procedures and techniques whose use varies from one case to another according to the degree of retardation and the type of behavior to be modified in the child. ${ }^{30}$ Behavioral therapy does not require language or verbal skills, so it is suitable for the mentally disabled. ${ }^{31}$ Cases of mental disabilities require the availability of psychological treatment programs to confront emotional and behavioral disorders caused by mental disability, which may arise from the social conditions surrounding the child and the negative attitudes of others towards it. ${ }^{32}$ This is represented in the psychological counseling program for parents and their assistance in accepting their child, methods of treatment, and the necessary health treatment directions for the child. ${ }^{33}$ Psychotherapy also includes programs that change attitudes towards mental disability, especially the attitudes of people who deal directly with the mentally disabled, namely par- ents, normal brothers and sisters, teachers and all those responsible for raising and rehabilitating children. ${ }^{34,35}$

Martin \& Pear ${ }^{36}$ refer to the employment and use of the concept of behavior modification, strategies and methods with mentally disabled children. By fixing desirable forms of behavior or changing undesirable forms of behavior to desirable forms of behaviour.

The studies related to the issue of non-adaptive behavior have indicated that the rate of its incidence among the mentally disabled who are enrolled in private institutions is relatively high. ${ }^{37}$ Weenink ${ }^{38}$ found that the percentage of behavioral problems among the mentally disabled exceeds their percentage among the normal. The results of the study showed that the rate of aggressive behavior was more frequent among mentally disabled children. In addition, Schwartz et $\mathrm{al}^{39}$ indicated that the prevalence of aggressive behavior among mentally disabled children ranged from $9 \%-34 \%$.

Aggressive behavior is defined as: "every observable, identifiable, and measurable behavior that takes multiple forms, and it is either physical or verbal, direct or indirect, and which is characterized by continuity and repetition. Aggressive behavior is expressed as an individual's deviation from social norms and results in physical and psychological harm. This behavior may tend to harm the individual him/ herself. 40

The expressions of aggression differ according to age and culture, as well as the method of education, upbringing, psychological and moral formation on which the individual grew up. ${ }^{41}$ The expression of aggression is represented in many physical forms, including aggressive feelings, angry looks through the eyes or using the mouth by issuing sounds of condemnation, or contempt with the hands or feet and actually using them to harm by hitting and kicking 
as it comes through the whole body by throwing on the ground, kicking, cramping and fainting. ${ }^{42,43}$

In view of the limited capabilities of these mentally disabled children that do not allow them to fully benefit from the activities practiced by other normal children, they also need a special kind of care that helps them to invest those limited abilities to the fullest extent possible, through guided programs by playing, which is the only outlet about their emotions, and mitigating the behavioral problems that a disabled child is exposed to, such as aggressive behavior. ${ }^{33}$ Mentally disabled children are not limited to a lack of mental competence, but they also suffer from several behavioral and emotional problems as a result of the unfavorable social, psychological and educational conditions they are exposed to appropriate during the stages of their lives and their upbringing. 40

The field of education and training for the disabled has clearly developed, and the behavioral problems associated with mentally disabled children are a source of primary concern for the family and for people who work directly with them, whether in private or public institutions. The aggressive behavior of mentally disabled children is on the list of behavioral problems because of its negative impact on the mentally disabled child and his/her family. It also makes the child an unacceptable person in the social and educational environment with which he/she interacts. ${ }^{44}$

Anastopoulos \& King 45 emphasize the importance of therapeutic methods based on group activity because they depend on re- and correcting wrong attitudes and reactions such as introversion, shyness and aggressive behavior, by providing the opportunity for the behaviorally disturbed child to participate actively in the peer group. This is done by giving the behaviorally disturbed child the opportunity to participate actively in the peer group, which provides the full opportunity for the behaviorally disturbed children to reduce the severity of aggressive behavior and stress.

Play is a diagnostic and therapeutic tool at the same time as it unloads the internal repressions of children, and thus reduces the severity of problems and behavioral and psychological disorders in general and aggressive behavior in particular, as it teaches them and earns them social skills, and this was confirmed by some studies on the importance of the role of play in emotional venting. 46

The researchers reached a set of studies related to the topic of the research, including: Quaish study, ${ }^{47}$ which aimed to reveal the effectiveness of a counseling program in reducing aggressive behavior among a sample of students consisting of (26) students who were characterized by aggressive behavior and they were divided equally. The two study tools were applied, namely the aggressive behavior scale and the counseling program. The study concluded that there are statistically significant differences between the mean scores of the two groups after applying the program and in favor of the experimental group, and this indicates the effectiveness of the behavioral counseling program. In addition, there were no differences in the mean scores of the experimental group members in the post and follow-up measurements, which indicated the continuity of the effectiveness of the behavioral counseling program.

Al-Khawaldeh and Jaradat ${ }^{48}$ conducted a study aimed at revealing the effectiveness of a counseling program in re- ducing aggressive behavior and strategies for dealing with it among a sample of students consisting of (36) students who are characterized by aggressive behaviour. The participants were divided equally into two groups, a control and an experimental group, and the two study tools were applied, namely, the anger scale, the strategies scale, and the behavioral counseling program. The study concluded that there are statistically significant differences between the mean scores of the two groups after applying the program in favor of the experimental group, and this indicated the effectiveness of the Behavioral guidance program.

Tsiouris et $\mathrm{l}^{49}$ conducted a study aimed at knowing the relationship between mental disability and aggressive behavior. The study sample consisted of 4069 participants in New York State, from normal individuals and individuals with mental disabilities. The researchers used the items of the Aggressive Behavior Scale (IBR-MOAS). The results indicated an increase in the rate of aggression among people with mental disabilities, whether verbal, physical or directed towards others, in addition to an increase in the rate of aggressive behavior among males more than females.

In the study of Al-Badawi, ${ }^{50}$ which aimed to identify the effectiveness of a counseling program based on the art of the story to reduce the aggressive behavior of the mentally disabled who are able to learn, the study sample consisted of (16) students of the mentally disabled who are able to learn, where they were divided into two experimental groups that include ( 8 males -8 females). The results revealed the following: The relative weight before applying the program was (61.7\%), and this indicated a higher than average level in aggressive behavior. The relative weight of the study sample was (42.1\%) after applying the program, this indicated an improvement in the experimental group, and that the relative weight of the study sample reached (40\%) after the follow-up measurement, which indicated the survival of the program's effect.

Saleh and Al-Banna ${ }^{21}$ conducted a study to investigate the effectiveness of a counseling program in alleviating the severity of aggressive behavior among children with mental disabilities who are able to learn. The study sample consisted of forty children with disabilities, who were distributed equally into an experimental and a control. The researchers used the scale of aggressive behavior and the intelligence scale. The study found that there were statistically significant differences at the level of significance $(\alpha<0.01)$ between the mean scores of the experimental group and the control group and in favor of the experimental group after applying the program.

Al-Junaidi ${ }^{51}$ conducted a study aimed at preparing a training program for mentally disabled children based on the use of the illustrated activity table to teach them and verify the effectiveness of the tables in reducing aggressive behavior. The study sample consisted of (20) mentally disabled children who are able to learn, and they were divided into two groups (10) experimental and (10) control. The aggressive behavior scale and the training program were used in this study. The results showed the following: - There are differences between the experimental group and the control group in the post measurement in favor of the experimental group. 
The study of Al-Bahas, ${ }^{52}$ which aimed to reveal the effectiveness of a joint training program in which parents and teachers are involved, and through the techniques of modifying non-aversive behavior such as reinforcement, extinguishing and environmental modification, in order to reduce the severity of self-harm behavior and improve the level of social interactions among a sample of mentally disabled children of moderate degree who are able to learn, the self-harming behavior scale was used. The results revealed the effectiveness of the program in reducing the severity of self-harming behavior among the experimental group members

Al-Asraj ${ }^{53}$ study aimed to identify the effectiveness of using the symbolic reinforcement method in controlling the behavioral problems of people with Down syndrome in the city of Riyadh. The researcher used the experimental method, adaptive behavior scale, and data collection form. The study sample consisted of (9) children aged (12-15) years. The researcher used the arithmetic mean, standard deviation, t-test, and one-way analysis of variance. The results revealed the following: There were significant statistical differences between the pre and post measurements in favor of the post-measurement. The study showed a significant effectiveness of the symbolic reinforcement program in reducing some behaviors after the application of the program and in the follow-up measurement.

The study found that there were statistically significant differences at the level of significance $(\alpha \leqslant 0.05)$ in terms of the value of $(\mathrm{z})$ and the level of significance between the aggressive behavior of the study sample members in the two applications, pre and post, at the level of each domain of aggressive behavior (self-directed aggression, and Aggression directed towards others, and aggression directed towards property) as well as the total level of aggression, and by reference to the mean score, it appears that the average aggressive behavior in the post application is lower than in the pre application, which indicates a decrease in aggressive behavior after the study sample members were exposed to the counseling program. This findings ensured the effectiveness of the counseling program in reducing the aggressive behavior of people with mild mental disabilities.

The current result of the study, which indicated the effectiveness of the behavioral counseling program, can explain that the sessions of the program have contributed to reducing aggressive behavior towards others through the development of many values among the members of the experimental group, and their acquisition of some criteria to maintain them, as well as decreased Aggressive behavior towards the self of the experimental group members by modifying their negative attitudes towards themselves, and training them in techniques that help replace positive behaviors instead of negative ones. The aggressive behavior towards property was also reduced among the experimental group members by modifying their negative attitudes towards property and emphasizing the importance of property and the need to preserve it.

The researchers attributed this to the program's attractiveness to individuals and techniques aimed at helping them develop their cognitive abilities to the maximum extent possible, work to reduce their negative thinking and train them on how to overcome their disturbing feelings, as well as safe interaction with social situations during the program's sessions.

The results of the current study agreed with the results of previous studies, which focused on reducing aggressive behavior by using behavioral counseling techniques, as in the study Saleh and Al-Banna ${ }^{20}$ and the study of Al-Bahas. ${ }^{52}$ The current study was similar to some studies in the results it reached, in which the aggressive behavior scale was used, such as: the study of Quaish, ${ }^{47}$ the study of Al-Khawaldeh and Jaradat, ${ }^{48}$ the study Al-Badawi, ${ }^{50}$ the study of Kim, ${ }^{30}$ the study of Al-Junaidi, ${ }^{51}$ and the study of Saleh and AlBanna. ${ }^{20}$

The study also found that there were no statistically significant differences at the level of significance $(\alpha \leqslant 0.05)$ in the post and follow-up applications at the level of each domain of aggressive behavior (self-directed aggression, aggression directed towards others, and aggression directed towards property) as well as the total level of the aggressive behaviors scale. This is due to the fact that the counseling program sessions provided a great deal of emotional venting and dialogue among the study sample, and that these techniques benefited them in unloading their energies, and this is consistent with the result of the study Quaish. ${ }^{47}$

\section{RECOMMENDATIONS}

Based on the fidnings of the present study, it would be recommended to adopt and apply such programs when dealing with people with mental disabilities, and benefiting from the results of the current study in reducing the severity of aggressive behavior among the mentally disabled through the application of the program on people with mental disabilities

In addition, the study recommends building more extended counselling programs based on the activities used in this study to improve mentally disabled students social interaction skills and reduce their unwanted behaviors.

Moroever, the present study recommends the curriculum designers and developers to include counselling program activitie in the curriculum designed for mild mentally disabled individuals in order to improve their behaviors and reduce their aggressive behaviors. 


\section{REFERENCES}

1. Guralnick MJ. Early intervention for children with intellectual disabilities: An update. J Appl Res Intellect Disabil. 2017;30(2):211-229. doi:10.1111/jar.12233

2. Trautmann S, Rehm J, Wittchen $\mathrm{H}$. The economic costs of mental disorders: Do our societies react appropriately to the burden of mental disorders? EMBO Rep. 2016;17(9):1245-1249. doi:10.15252/emb r.201642951

3. Bogic M, Njoku A, Priebe S. Long-term mental health of war-refugees: a systematic literature review. BMC Int Health Hum Rights. 2015;15(1):1-41. doi:10.1 186/s12914-015-0064-9

4. Cornaglia F, Crivellaro E, McNally S. Mental health and education decisions. Labour Economics. 2015;33:1-12. doi:10.1016/i.labeco.2015.01.005

5. Atkins MA, Rodger S. Pre-service teacher education for mental health and inclusion in schools.

Exceptionality Education International. 2016;26(2). do i:10.5206/eei.v26i2.7742

6. Rankin J, Matthews L, Cobley S, et al. Psychological consequences of childhood obesity: psychiatric comorbidity and prevention. Adolesc Health Med Ther. 2016;7:125-146. doi:10.2147/ahmt.s101631

7. Copeland WE, Wolke D, Shanahan L, Costello EJ. Adult functional outcomes of common childhood psychiatric problems: a prospective, longitudinal study. JAMA Psychiatry. 2015;72(9):892-899. doi:10.10 01/jamapsychiatry.2015.0730

8. Sridevi G, George AG, Sriveni D, Rangaswami K. Learning disability and behavior problems among school going children. Journal of Disability Studies. 2015;1(1):4-9.

9. Tassé MJ, Luckasson R, Schalock RL. The relation between intellectual functioning and adaptive behavior in the diagnosis of intellectual disability. Intellectual and developmental disabilities. 2016;54(6):381-390. doi:10.1352/1934-9556-54.6.381

10. Kirchner R. Investigation into the Medical, Developmental, and Adaptive Behavior Phenotype of Infants and Toddlers with Williams Syndrome (Doctoral dissertation, The Ohio State University).

11. Zureikat I, Al-Rihani S, Tanous A. Counseling for People with Special Needs and Their Families. 1st ed. Dar Al-Fikr Publishing and Distribution; 2018.
12. Price M, Salzer MS, O’Shea A, Kerschbaum SL. Disclosure of mental disability by college and university faculty: The negotiation of accommodations, supports, and barriers. Disabil Stud Q. 2017;37(2). doi:10.18061/dsq.v37i2.5487

13. Lassila ET, Timonen V, Uitto M, Estola E. Storied emotional distances in the relationships between beginning teachers and school principals. Br Educ Res J. 2017;43(3):486-504. doi:10.1002/berj.3280

14. Tough H, Siegrist J, Fekete C. Social relationships, mental health and wellbeing in physical disability: a systematic review. BMC Public Health. 2017;17(1):1-8. doi:10.1186/s12889-017-4308-6

15. Al-Rousan FA. Introduction to Mental Disability. Amman; 2013.

16. Giedd JN, Raznahan A, Alexander-Bloch A, Schmitt E, Gogtay N, Rapoport JL. Child psychiatry branch of the National Institute of Mental Health longitudinal structural magnetic resonance imaging study of human brain development.

Neuropsychopharmacol. 2015;40(1):43-49. doi:10.103 8/npp.2014.236

17. Altundağ S, Çalbayram NÇ. Teaching menstrual care skills to intellectually disabled female students. $J$ Clin Nurs. 2016;25(13-14):1962-1968. doi:10.1111/ioc $\underline{\text { n.13215 }}$

18. Mullen KJ, Staubli S. Disability benefit generosity and labor force withdrawal. Journal of Public Economics. 2016;143:49-63. doi:10.1016/i.jpubeco.201 $\underline{6.08 .007}$

19. Pears KC, Kim HK, Healey CV, Yoerger K, Fisher PA. Improving child self-regulation and parenting in families of pre-kindergarten children with developmental disabilities and behavioral difficulties. Prev Sci. 2015;16(2):222-232. doi:10.1007/s11121-01 4-0482-2

20. Saleh A, Al-Banna A. The Effectiveness of a Counseling Program to Reduce the Violence of the Aggressive Behavior of Mentally Handicapped Children who are able to Learn in Gaza Governorate. Human Sciences Series. 2008;10(1):51-83.

21. Munir KM. The co-occurrence of mental disorders in children and adolescents with intellectual disability/intellectual developmental disorder. Curr Opin Psychiatry. 2016;29(2):95-102. doi:10.1097/yco.0 000000000000236 
22. Ji NY, Findling RL. Pharmacotherapy for mental health problems in people with intellectual disability. Current Opinion in Psychiatry. 2016;29(2):103-125. $\underline{\text { do }}$ i:10.1097/yco.0000000000000233

23. Adler M, Huber JT, Nix AT. Stigmatizing disability: Library classifications and the marking and marginalization of books about people with disabilities. The Library Quarterly. 2017;87(2):117-135. doi:10.1086/690734

24. Hogan AJ. Social and medical models of disability and mental health: evolution and renewal. CMAJ. 2019;191(1):16-18. doi:10.1503/cmaj.181008

\section{Perlin ML, Cucolo HE, Lynch A. Mental Disability} Law: Cases and Materials. Carolina Academic Press; 2017.

26. Merten T, Rogers R. An international perspective on feigned mental disabilities: Conceptual issues and continuing controversies. Behav Sci Law.

2017;35(2):97-112. doi:10.1002/bsl.2274

27. Yılmaz A, Soyer F. Effect of physical education and play applications on school social behaviors of mildlevel intellectually disabled children. Education Sciences. 2018;8(2):89. doi:10.3390/educsci8020089

28. Dobson D, Dobson KS. Evidence-Based Practice of Cognitive-Behavioral Therapy. Guilford publications; 2018.

29. Lorenzo-Luaces L, Keefe JR, DeRubeis RJ. Cognitive-Behavioral Therapy: Nature and relation to non-cognitive behavioral therapy. Behav Ther. 2016;47(6):785-803. doi:10.1016/j.beth.2016.02.012

30. Kim YK, Choi J, Park SC. A novel biopsychosocial-behavioral treatment model in schizophrenia. Int J Mol Sci. 2017;18(4):734. doi:10.33 90/ijms18040734

31. Kazantzis N, Luong HK, Usatoff AS, Impala T, Yew RY, Hofmann SG. The processes of cognitive behavioral therapy: A review of meta-analyses. Cogn Ther Res. 2018;42(4):349-357. doi:10.1007/s10608-01 $\underline{8-9920-\mathrm{y}}$

32. Johnsen TJ, Friborg O. The effects of cognitive behavioral therapy as an anti-depressive treatment is falling: A meta-analysis. Psychological Bulletin. 2015;141(4):747-768. doi:10.1037/bul0000015

33. Ali AS. Efficiency of intervention counseling program on the enhanced psychological well-being and reduced post-traumatic stress disorder symptoms among Syrian women refugee survivors. Clin Pract Epidemiology Ment. 2020;16(Suppl-1):134-141. doi:1 $\underline{0.2174 / 1745017902016010134}$
34. Lyon AR, Dorsey S, Pullmann M, Silbaugh-Cowdin J, Berliner L. Clinician use of standardized assessments following a common elements psychotherapy training and consultation program. Adm Policy Ment Health. 2015;42(1):47-60. doi:10.100 7/s10488-014-0543-7

35. Davies LE, Oliver C. Self-injury, aggression and destruction in children with severe intellectual disability: Incidence, persistence and novel, predictive behavioural risk markers. Res Dev Disabil. 2016;49-50:291-301. doi:10.1016/j.ridd.2015.12.003

36. Martin G, Pear J. Behavior Modification: What It Is and How to Do It. Routledge; 2019. doi:10.4324/97804 $\underline{29020599}$

37. Tarsidi I, Suherman Y, Wibowo SW. Effectiveness of Behavior Modification Models on Reducing of NonAdaptive Behavior in Children with Intellectual Disability. Adv Sci Lett. 2019;25(1):204-207. doi:10.11 66/asl.2019.13219

38. Weenink AW. Behavioral problems and disorders among radicals in police files. Perspectives on terrorism. 2015;9(2):17-33.

39. Schwartz JA, Beaver KM, Barnes JC. The association between mental health and violence among a nationally representative sample of college students from the United States. PLOS ONE. 2015;10(10):e0138914. doi:10.1371/journal.pone.013 $\underline{8914}$

40. Barlett C, Oliphant H, Gregory W, Jones D. Egodepletion and aggressive behavior. Aggr Behav. 2016;42(6):533-541. doi:10.1002/ab.21648

41. Teranishi Martinez C. Engendered expressions of aggression: The role of gender, proprietary behaviors, and jealousy in intimate partner violence. Violence Gend. 2015;2(2):112-118. doi:10.1089/vio.2014.0040

42. Hills DJ. Defining and classifying aggression and violence in health care work. Collegian. 2018;25(6):607-612. doi:10.1016/j.colegn.2018.08.002

43. Fjermestad-Noll J, Ronningstam E, Bach BS, Rosenbaum B, Simonsen E. Perfectionism, shame, and aggression in depressive patients with narcissistic personality disorder. Personal Disord. 2020;34(Supplement):25-41. doi:10.1521/pedi.2020.3 4.supp. 25

44. Noorbala AA, Faghihzadeh S, Kamali K, et al. Mental health survey of the Iranian adult population in 2015. Archives of Iranian medicine. 2017;20(3). 
45. Anastopoulos AD, King KA. A cognitive-behavior therapy and mentoring program for college students with ADHD. Cogn Behav Pract. 2015;22(2):141-151. do i:10.1016/j.cbpra.2014.01.002

46. Tonkin A, Whitaker J, eds. Play in Healthcare for Adults: Using Play to Promote Health and Wellbeing across the Adult Lifespan. Routledge; 2016. doi:10.432 4/9781315679846

47. Quaish M. The Effectiveness of Psychological and Educational Counseling in Reducing the Aggressive Behavior of a Sample of Students [PhD]. University of Oran 2, Algeria; 2017.

48. Al-Khawaldeh O, Jaradat A. The effect of a cognitive-behavioral treatment program in reducing anger and improving strategies for dealing with it. Mu'tah for Research and Studies. 2014;29(2):81-104.

49. Tsiouris JA, Kim SY, Brown WT, Cohen IL. Association of aggressive behaviours with psychiatric disorders, age, sex and degree of intellectual disability: a large-scale survey. Journal of Intellectual Disability Research. 2011;55(7):636-649. doi:10.1111/ j.1365-2788.2011.01418.x
50. Al-Badawi Z. The Effectiveness of a Counseling Program Based on Story Art to Reduce the Aggressive Behavior of Learnable Mentally Handicapped Persons [Master]. College of Education, Islamic University; 2011.

51. Al-Junaidi H. A Proposed Program for Using Pictorial Activity Schedules to Reduce Aggressive Behavior among Mentally Disabled Children Who Can Learn in Gaza Governorate [Master]. Faculty of Education, Al-Azhar University; 2007.

52. Al-Bahas S. The effectiveness of an integrative training program to reduce self-harm behavior and improve social interactions in mentally disabled children. J Coll Educ. 2007;6(2):421-486.

53. Al-Asraj A. The Effectiveness of the Symbolic Reinforcement Method in Controlling Behavioral Problems in Down Syndrome [Master]. College of Graduate Studies, Department of Social Sciences, Naif University for Security Sciences, Riyadh; 2007. 